\title{
New tools for teaching: educational cards for primary schools on the prevention of food waste
}

\author{
Elena Comino, Francesca Macioce
}

Department of Environment, Land and Infrastructure Engineering, Polytechnic of Turin, Italy

\begin{abstract}
This article shows the results obtained from the creation of some educational cards for primary school pupils on the topic of the food waste prevention. The collaboration between designers and experts in the educational field was fundamental for this project: we combined the communicative and design skills of the designer with the didactics knowledge of the educators. The activities have been created on the basis of the experiential methodology, the pupils feeling themselves the protagonist of the activities, combining the traditional educational activities, also trough cross-learning of good ecological practices. The proposed activities explore the life cycle of an aliment from when it is purchased by the consumer until it is disposed of, analysing in which stages the consumer wastes food. The exercises were created to understand how to avoid or reduce food waste in those specific phases. The result of the project is composed of two different books containing the educational cards, one for teachers and families with basic information on exercises and the other one for students containing the exercises. The final objective of the educational cards is to sensitize students and adults around them on the food waste problem.
\end{abstract}

Keywords: Educational Cards; Food Waste; Education; Experiential methodology; Primary School; Visual Communication. 


\section{Introduction}

Food waste is an alarming problem for both sustainable development and nutrition. Globally, a third of the food available (Buchner et al., 2012; Segrè and Azzurro, 2016; MATTM, n.d.), which amounts to 1.3 billion tons per year (FAO, 2013), is lost or wasted resulting in a series of negative impacts in the environmental, economic and social ethics(Marsden and Morley, 2014; BCFN, 2015). The research shows that in Italy 6.6 million tons (Segrè and Falasconi, 2011) are due to the wrong behaviour of the final consumer for the lack of knowledge about food and nutrition (WW, 2013; COOP, 2016).

To educate people on these issues we decided to design educational cards for primary schools (Bellantone, 2018; FMPS, n.d.) that would develop a new behavioural paradigm on aliment in the new generations (GU, 2016; Tringali, 2018). The project is designed as an educational path for the environmental and food education to use at school and at home that include seven educational cards contained in two different books.

In the design process of the books the support of two experts in the field of child education were fundamental: by a teacher from the primary school of Bollengo (Ivrea, Italy) and by a head of the Education Office of Slow Food Italia in Bra. The collaboration with these educators has allowed the designer to integrate some necessary information into the didactic project and to be able to validate the activities designed to be included in the pupils' study plan (MIUR, 2012, 2016).

In order to respect the pupils' study plans, the educational cards have been designed to develop simultaneously both ecological pratices and school subjects. In fact, in the activities there are a series of exercises on waste food in relation to school subjects, for example: for mathematics, exercises with numbers, units of measure and equivalences; for Italian, activities with new terminologies and synthesis skills are learned; in science, exercises to learn components and life cycle of an aliment. Furthermore, great importance is given to solicit of the capacity of collaboration amoung classmates, of communication skills and hypothesis formulation.

\section{Concept}

The main objectives that the project aims to achieve are awareness of the issues of waste and the topics linked to it: in learning the values and characteristics of food, highlighting how waste can return to a resource, in the development of sustainable behaviours to adopted in everyday life and in the awareness of the importance of personal and collective actions to reduce food waste (Macioce, 2018).

The educational cards are focused on the life cycle of an aliment from when it comes into contact with the final consumer to it being disposed of. We divided these phases in the seven 
main stages: knowledge, purchase, storage, processing, waste, reuse and disposal (Figure 1). The decision to analyse these phase of the food is to underline the importance of personal actions and choice during each stage to better understand to what is due to the creation of the food waste and what we can do to avoid it (EXPO, 2015). The principal aliment on which the educational cards are based is the tomato because its easy availability and to the simplicity with which the food waste can be treated.

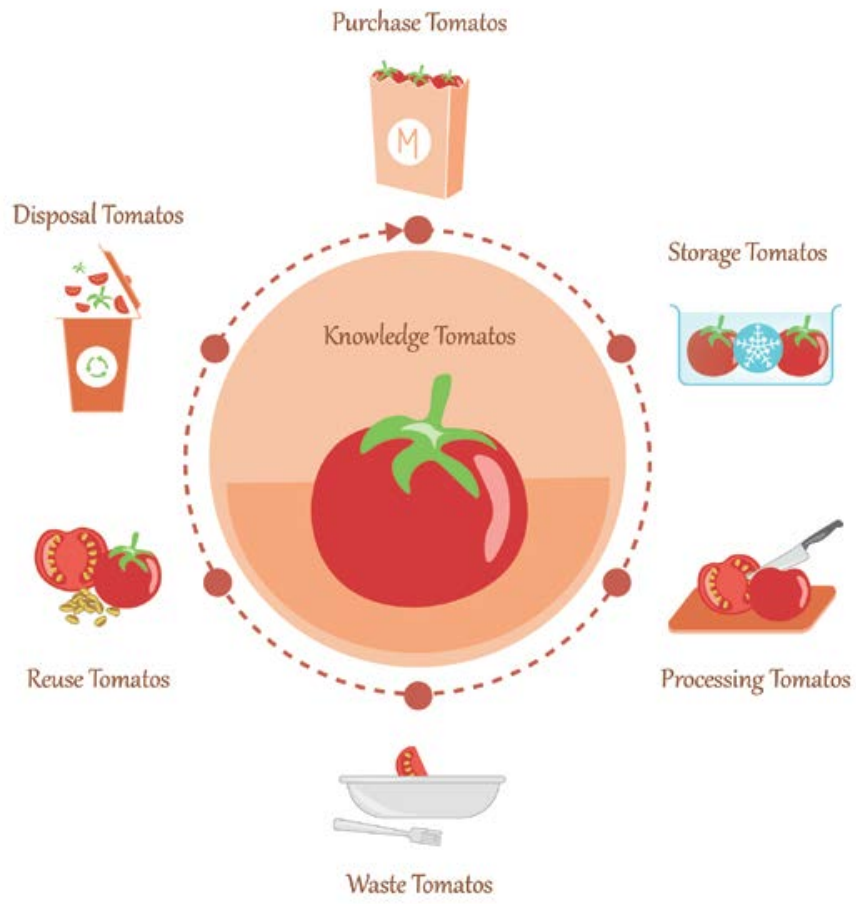

Figure 1. The seven stages of the life cycle of the tomato corresponding to the seven exercises

The target who the project is focused on are primary school pupils, particularly children aged 8 to 10, who attend 3rd-4th-5th grade. It was decided to focus on this age group for different reasons related to the children and their skills: they are independent in using kitchen or gardening tools, they have more ability to formulate hypotheses and solutions, and have competences of language and synthesis (Comino and Macioce, 2019).

All tools developed to educate students to be included in the teaching plans, must follow a series of guidelines and must comply with a series of new methodologies focused on the development of skills, including transversal and soft skills (Calvani and Menichetti, 2015). One of these methods used to develop our educational cards is based on centrality: involving the student in an experiential way to the training activity; making him feel an active part of the educational action; supporting him with the information on the topic and giving him a 
good example; stimulating him in the achievement of the objectives and in the formulation of innovative solutions; allowing it to acquire greater awareness on the issue. During the activities the supervision of the educators is fundamental, which allowed to be able to design the didactic cards in compliance with the educational methodologies and the necessary precautions.

To create the educational cards is another fundamental factor were the illustrative and graphic skills of the designer. Visual communication is fundamental for education, it represents a support for education, stimulating learning and mnemonic processes and having a highly inclusive reading, it also allows children with special needs to learn more easily (Paivio, 2006; Menichetti and Sarro, 2015; Calvani, 2011).

\section{Results: the educational cards structure}

The designed cards are grouped into two books, one for teachers and families, and another for pupils, and they are communicate with each other. The first is a sort of booklet of instructions useful for teachers and families to support the pupils during the exercises, inside all the information essential to carry out the activities can be found. This book, contains fundamental information to allow the activity to be inserted correctly within the pupils' study plan.

The second book is for pupils, it contains the exercises to be performed. All the exercises are divided into different phases, with a first part that illustrates the negative impacts of food waste, the reasons why the exercises are going to be performed and how to reduce or eliminate that negative impact.

Analysing one of this educational cards it's possible to better understand the composition of the activities, the contents and the goals. The educational card "Waste Tomatos" is about one of the moments of greatest food waste that takes place inside houses and school canteens: the leftovers. The focus of this exercise is mainly to get aware on the problem of the leftovers and of the negative impact that creates.

To allow to pupils to understand the real problem, in the first part (Figure 2.) of the educational card provides information on the quantities and types of aliments that people mainly wastes in Italy. The second part (Figure 3.) of the exercise is based on collaboration between classmates: they have to weigh all the leftovers occurred in the canteen during the meal. In this way, pupils understand how much food it was waste.Through these activities the pupils perceives the importance of the personal and collective actions that must be taken in order to reduce the food waste.

At this stage, it would be necessary for the teacher to coordinate the activity and collect feedback on the progress of the exercise: creating a moment of sharing with the pupils to 
discuss on the results obtained, to talk about the activities and to find solutions to reduce the leftovers during the meal (Figure 4.).

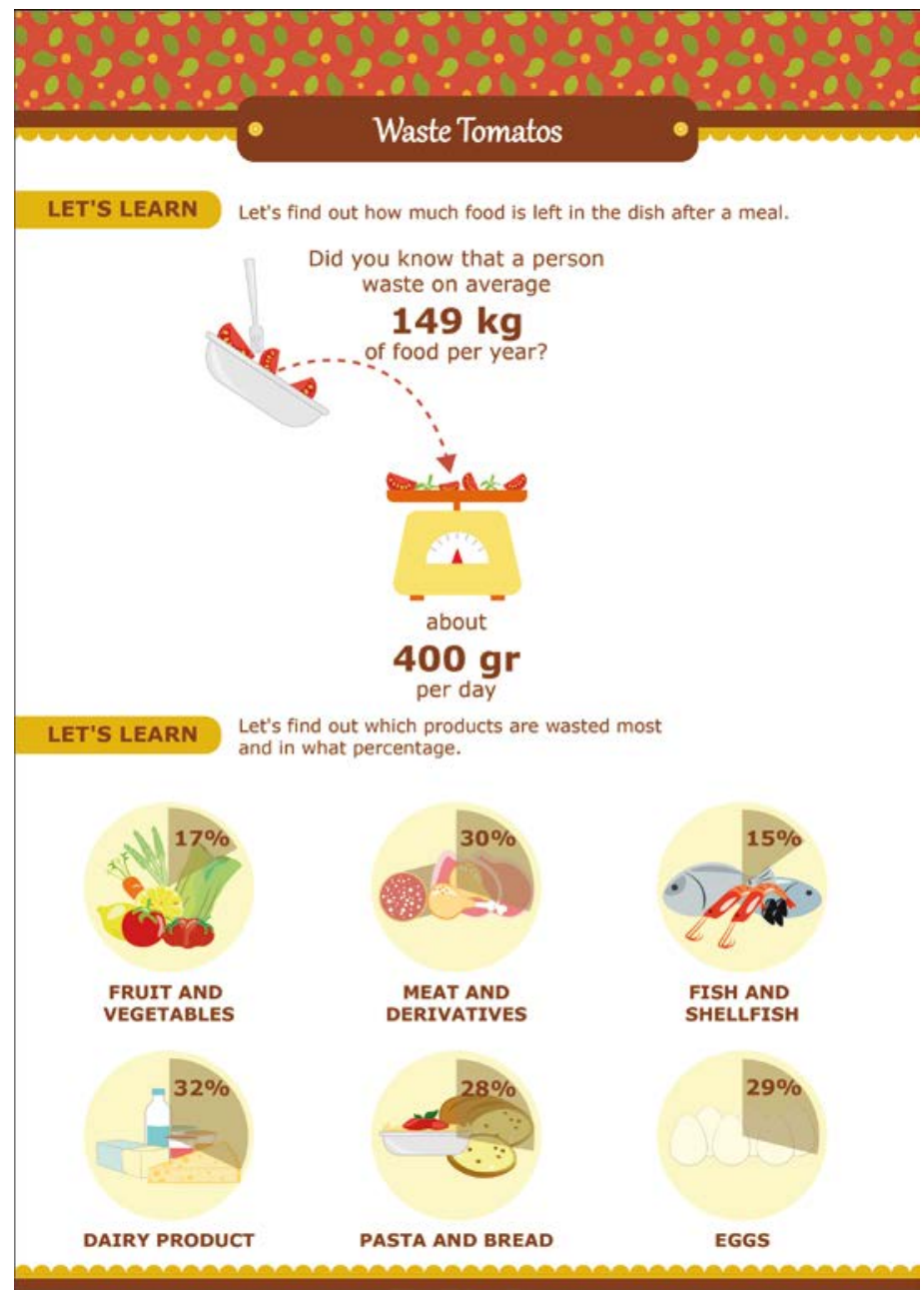

Figure 2. Exaple of the first part of the educational card "Waste Tomatos"

\section{Conclusion: future developments}

The educational cards are ready for experimentation in primary schools and we are currently looking for funding to print copies of the books and to distribute to local schools interested in the initiative.

The experimentation should start from the beginning of spring until the end of summer, respecting the seasonality of the food on which the exercises are focused. The objective of 
the experimentation is to collect as many feedbacks as possible from teachers and families so as to be able to understand if the project has achieved the intended objectives and implement the project. The experimentation will be monitored by verifying the results of the educational forms and by analyzing the data obtained from the questionnaires that will be submitted to the teachers.

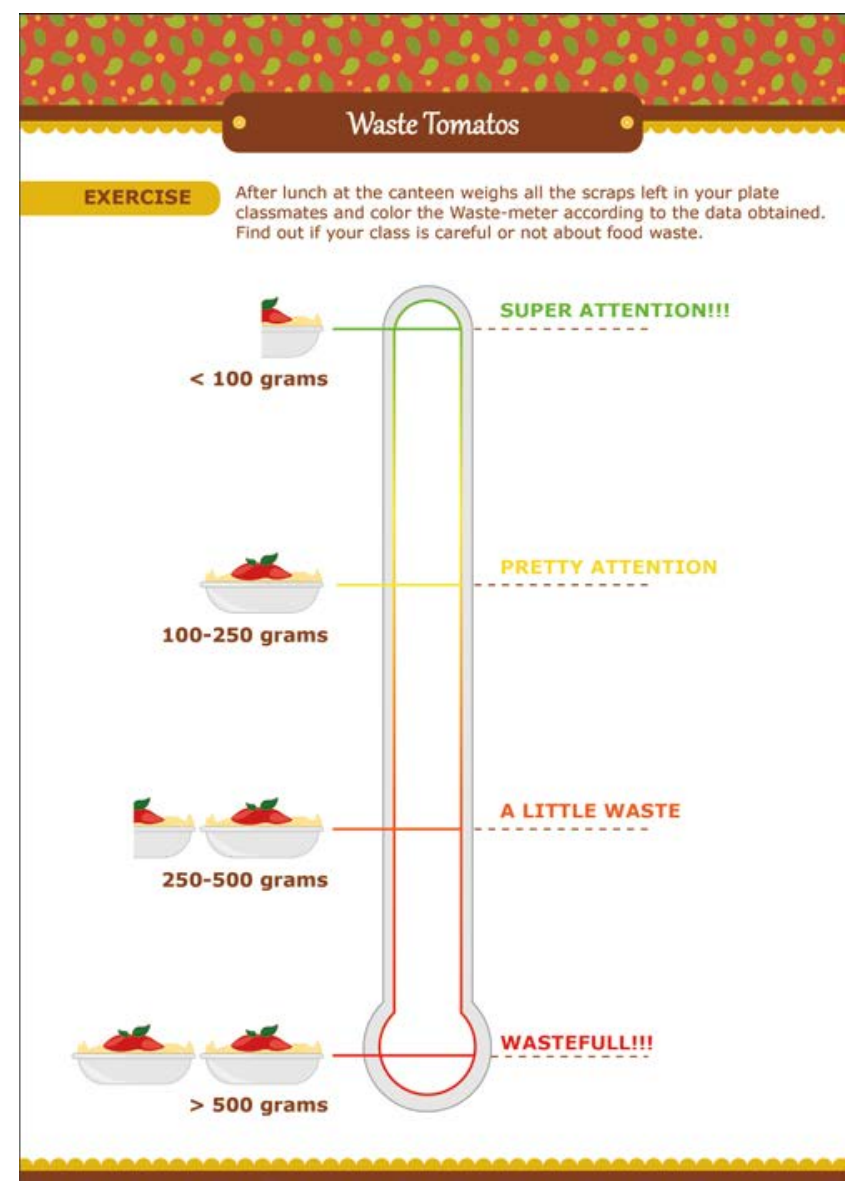

Figure 3. Example of the second part of the educational card "Waste Tomatos"

Through these educational cards we hope to sensitize children on the food waste problems, to raise awareness of the adults around the pupils that are called to participate actively in the proposed activities. The strong synergy between the student and the family is necessary for the success of the project and to positively influence adults in their daily actions, to which they are required to learn, share, formulate hypotheses and experiment with the student. 


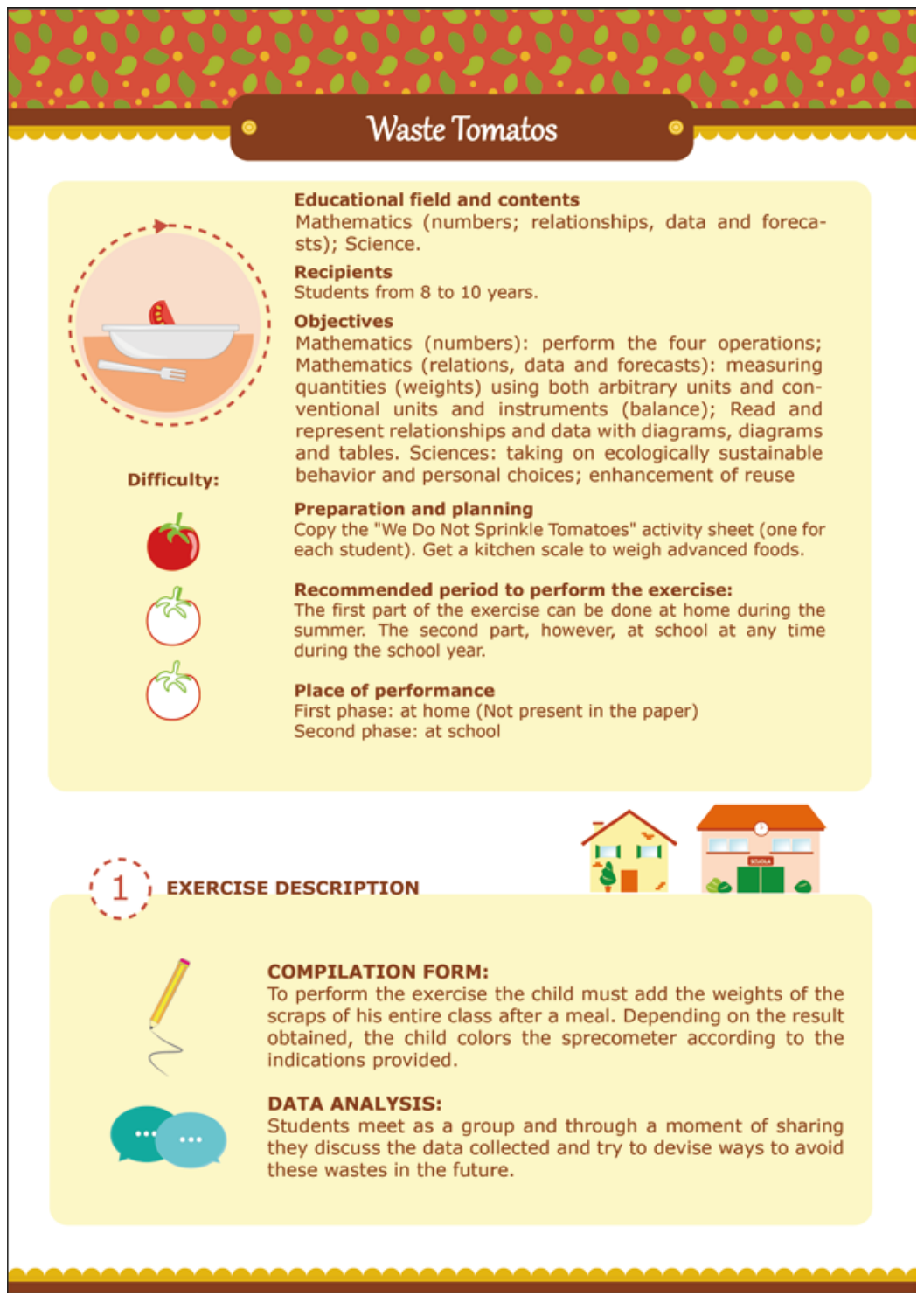

Figure 4. Example of the educational card for teachers and families "Waste Tomatos".

\section{References}

(BCFN) Fondazione Barilla Center for Food \& Nutrition (2015). Protocollo di Milano sull'Alimentazione e la Nutrizione

Bellantone, R. 2018. Spreco alimentare, cosa dice la legge Gadda, Unione Nazionale dei Consumatori, UNC. (Accessed 27/06/18) 
New tools for teaching: Educational cards for primary schools on the prevention of food waste

Buchner, B. et al. (2012). Lo spreco alimentare: cause impatti e proposte. Barilla Center for Food \& Nutrition. Parma: Codice Edizioni. (Accessed 29/10/18)

Calvani, A. (2011a). Principi dell'istruzione e strategie per insegnare. Criteri per una didattica efficace. Roma: Carocci.

Calvani, A. and Menichetti L. (2015). Come fare un progetto didattico. Gli errori da evitare. Carocci. ISBN 9788874667369

Comino E. and Macioce F. (2019). "Collaboration between designer and educators: design of educational cards to prevent food waste” Design and Culture. (Sumbitted)

Coop (2016). Rapporto Coop 2016. Conferenza stampa. Milano. (Accessed 6/06/18)

(EXPO) Expo Milano (2015). Rapporto di sostenibilità (Accessed 9/07/18)

(FAO) Organizzazione delle Nazioni Unite per l'alimentazione e l'agricoltura (2013). Food wastage footprint: Impacts on natural resources. Summary Report. ISBN 978-92-5107752-8. (Accessed 10/7/18)

(FMPS) Fondazione Monte dei Paschi di Siena. n.d. SCOOL FOOD, dal banco alla tavola. Barilla Center for Food and Nutrition Foundation. (Accessed 5/06/18)

(GU) Gazzetta ufficiale della Repubblica Italiana. 2016. Anno $157^{\circ}$ - Numero 202, 30 Agosto 2016 (Accessed 2/07/18)

Macioce, F. 2018. "Da spreco alimentare a Risorsa: progettazione di schede didattiche per le scuole primarie”. Working paper, Politecnico di Torino. (Accessed 5/11/18)

Marsden, T. and Morley A. (2014). Sustainable Food Systems: Building a New Paradigm. Abingdon, UK, and New York: Routledge. ISBN 9781136185427

(MATTM) Ministero dell'ambiente e della tutela del territorio e del mare. n.d. Perdite e sprechi alimentari I numeri del fenomeno. (Accessed 15/9/18)

Menichetti, L. and Sarro S. (2015). L'uso della comunicazione visiva nella scuola primaria: decorativismo o strumento cognitivo?. Form@re, Open Journal per la formazione in rete. Numero 2. Volume 15.pp. 75-94. ISSN 1825-7321.

(MIUR) Ministero dell'Istruzione, dell’Università e della Ricerca (2012). Annali della Pubblica Istruzione, Indicazioni nazionali per il curricolo della scuola dell'infanzia e del primo ciclo d'istruzione.

(MIUR) Ministero dell’Istruzione, dell’Università e della Ricerca (2016).Traguardi di sviluppo delle competenze, PTOF dell'Istituto Comprensivo Statale di Azeglio.

Paivio, A. (2006). Mind and its evolution: A dual coding theoretical interpretation. Mahwah, NJ: Lawrence Erlbaum Associates.

Segrè, A., and Azzurro P. (2016). Spreco alimentare: dal recupero alla prevenzione: indirizzi applicativi della legge per la limitazione degli sprechi. Milano: Fondazione Giangiacomo Feltrinelli. ISBN 978-88-6835-278-3

Segrè, A. and Falasconi L. (2011). Il libro nero dello spreco in Italia: il cibo. Edizioni Ambiente. ISBN 978-88-66-27000-3

Tringali, S. (2018). 2018 Anno del cibo italiano. Primo: ridurne lo spreco. Centro studi cooperativi. (Accessed 28/06/18)

(WW) Waste Watcher (2013). Rapporto 2013 Waste Watcher - Knowledge for Expo. 